\title{
NEW REFERENCE SYSTEMS FOR THE CALIBRATION OF HV IMPULSES AT LNE
}

\author{
Hanane Saadeddine*, Mohamed Agazar, Dominique Fortune \\ LNE, Laboratoire National de métrologie et D’Essais, 29 Av Roger Hennequin 78197 Trappes, France.
}

\begin{abstract}
Driven by the need for traceable measurement methods, LNE has developed and characterized new reference measurement systems for the calibration of $H V$ impulses, including lightning impulses (1,2 $\mu s / 50 \mu s)$ and switching impulses $(250 \mu \mathrm{s} / 2500 \mu \mathrm{s})$, according to new requirements of IEC 60060-1 and IEC 60060-2. This paper describes new reference measurement systems, which have been developed and fully characterized at LNE. In addition, the paper describes the test procedure for accurate measurements especially for in-situ calibrations in 5 successive steps; measurements of radiofrequency disturbances, step response of voltage dividers, measurement of the scale factors of voltage dividers, calibration of digitizer's channels and ranges, measurement of the voltage linearity of the divider under calibration up to maximum voltage.
\end{abstract}

\section{INTRODUCTION}

The expansion of smart and future grids involve the use of control, diagnostic, connection and monitoring apparatus such as power transformers, circuit breakers, switchgear, insulators, power cables and connecting devices. These apparatus are exposed to high transient voltages due to internal and external over-voltages. Before commissioning, their reliability is tested with standard impulse voltages in HV test laboratories using HV reference measuring systems. The measurements include peak voltage value and time parameters (front time for lightening impulses (LI), time to peak for switching impulses (SI) and time to half value for both). The metrological traceability is performed by comparison to a reference measuring system in national metrology institute. For this purpose, LNE has upgraded the existing reference measuring system of LI measurements $(1,2 \mu \mathrm{s} / 50 \mu \mathrm{s})$ for voltages up to $420 \mathrm{kV}$ and has developed a new reference measuring system for SI measurements $(250 \mu \mathrm{s} / 2500 \mu \mathrm{s})$ for voltages up to $500 \mathrm{kV}$. The linearity extension up to $500 \%$ of the calibrated voltage level could be performed for the traceability of LI measurements up to $2.1 \mathrm{MV}$ and SI measurements up to 2.5 MV according to IEC 60060-1 [1] and 60060-2 [2].

\section{LNE HV REFERENCE SYSTEMS}

New reference measurement systems for the calibration of HV impulses have been developed at LNE to satisfy the new requirements of IEC 60060-1 (2010) and IEC 60060-2 (2010). They are composed of two HV dividers (figure 1); A homemade resistive divider is designed for LI measurements for peak voltages up to $420 \mathrm{kV}$. A mixed resistive capacitive divider is used for SI measurements for voltages up to $500 \mathrm{kV}$. Each divider is equipped with a damping resistor, adapted triaxle cable with an impedance of $75 \Omega$ and a length of $20 \mathrm{~m}$, digitizer and software for signal processing. The HV dividers are characterized to reach high accuracy, such as frequency linearity, voltage linearity, proximity effects, step response, convolution, temperature effects, self-heating effects, cable lengths effects, and radio frequency disturbances.

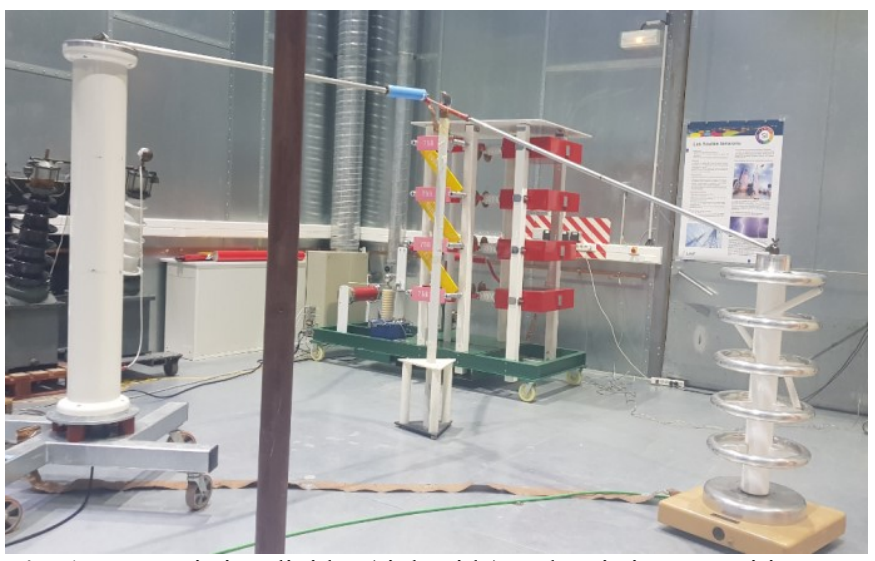

Fig. 1. H.V resistive divider (right side) and resistive-capacitive divider (left side) in LNE Faraday cage.

\subsection{Resistive high voltage divider for $\mathrm{LI}$}

The reference measuring system for LI is described in figure 2. The system is intended for the calibration of full LI $(1,2 \mu \mathrm{s} /$ $50 \mu \mathrm{s}$ ) or chopped LI down to $0,5 \mu \mathrm{s}$. The HV arm of the HV divider is composed of a $24 \mathrm{k} \Omega$ non-inductive wound resistor immersed in oil. To avoid proximity effects, along the HV resistive columns a uniform field distribution is produced by five toroidal screens whose potentials are fixed by additional capacitance chains. The low voltage arm of the divider is composed of two non-inductive resistors and it is grounded through a wide and copper foil of $20 \mathrm{~cm}$. The transmitting cable has an impedance of $75 \mathrm{Ohm}$ and it is terminated with the same impedance on both sides for a better matching. A $217 \Omega$ damping resistor with stainless steel tube of $2.4 \mathrm{~m}$ length are used at the HV lead.

\footnotetext{
* Corresponding author: hanane.saadeddine@lne.fr
} 


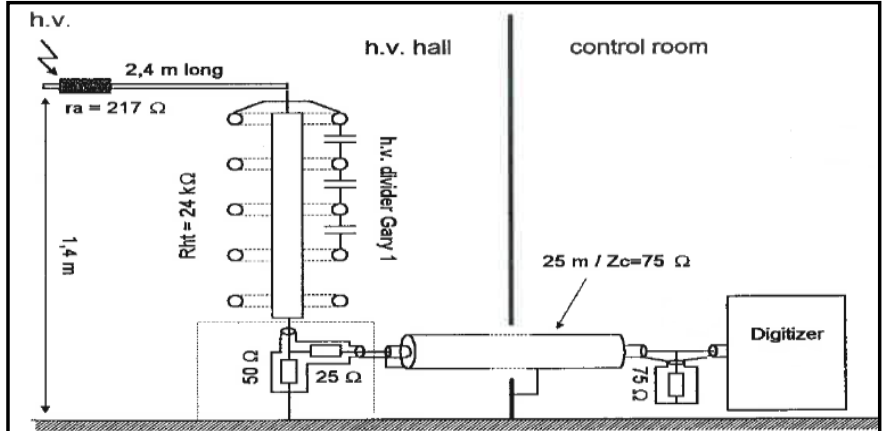

Fig. 2. LNE reference measuring system for lightening impulses.

The resistive divider has been fully characterized in [5] et [6] , it has the following characteristics:

- Scale factor : 978

- Bandwidth : $35 \mathrm{MHz}$

- Response time : $10 \mathrm{~ns}$

- Settling time : $70 \mathrm{~ns}$

- Overshoot : $20 \%$

- Frequency linearity $<0.1 \%(\mathrm{DC}-100 \mathrm{kHz})$

- Temperature coefficient $:<10 \mathrm{ppm} /{ }^{\circ} \mathrm{C}$

- Voltage linearity for LI $:<0.1 \%$.

To validate the measurements with the resistive divider, a comparison is arranged in order to compare the lightning impulse parameters measured by the resistive divider of LNE to those obtained with the HV resistive divider of EDF Les Renardières France, which, has been participated in international comparison and has been identified as a reference system for LI measurements. The comparison measurements have been done for three levels, $100 \mathrm{kV}$, $200 \mathrm{kV}$ and $300 \mathrm{kV}$ for long LI $(1.6 / 50 \mu \mathrm{s})$. other measurements have been performed for LI with front times of $0,4 \mu \mathrm{s}, 0,8 \mu \mathrm{s}$ and $1.2 \mu \mathrm{s}$. The results are summarized in the table 1 .

Table: Deference between Gary 1 and Gary 2.

\begin{tabular}{|c|c|c|c|c|}
\hline \multirow{2}{*}{ Voltage } & \multirow{2}{*}{ LI type } & \multicolumn{3}{|c|}{$\begin{array}{c}\text { Difference between Gary } 1 \\
\text { and Gary } 2 \\
(\%)\end{array}$} \\
\hline & & $\begin{array}{l}\text { Peak } \\
\text { Value }\end{array}$ & $\begin{array}{l}\text { Front } \\
\text { time }\end{array}$ & $\begin{array}{l}\text { Time to } \\
\text { half } \\
\text { value }\end{array}$ \\
\hline $100 \mathrm{kV}$ & \multirow{3}{*}{$1.6 / 50 \mu s$} & -0.03 & 0.20 & 0.22 \\
\hline $200 \mathrm{kV}$ & & -0.05 & 0.21 & 0.20 \\
\hline $300 \mathrm{kV}$ & & -0.06 & 0.20 & 0.16 \\
\hline \multirow{2}{*}{$300 \mathrm{kV}$} & $0.8 / 50 \mu \mathrm{s}$ & -0.12 & -0.04 & 0.22 \\
\hline & $1.2 / 50 \mu \mathrm{s}$ & -0.14 & -0.35 & 0.25 \\
\hline
\end{tabular}

According to the results, the two dividers are comparable each other and have the same metrological performances. The difference are less than $0.15 \%$ for the peak value, less than $0.35 \%$ for front time and $0,25 \%$ for the time to half value. The resistive divider has been participated for the international comparison of LI piloted by Euramet [7].

\subsection{Mixed resistive capacitive divider for SI}

The combined resistive-capacitive divider is used as a reference for the calibration of SI (time to peak in the range $20 \mu \mathrm{s}-300 \mu \mathrm{s}$ and time to half value in the range $1000 \mu \mathrm{s}$ $4000 \mu \mathrm{s})$. All the influence quantities have been carefully studied to ensure the best uncertainties. The predominant effect is the proximity effect which requires special provisions to be observed at the time of the measurements, namely the realization of a high-voltage assembly with good quality to eliminate or drastically decrease this effect. The divider has been fully characterized, it has the following characteristics:

- Resistive-capacitive divider

- Scale factor : 998

- Response time : $20 \mathrm{~ns}$

- Settling time : $700 \mathrm{~ns}$

- Overshoot : $23 \%$

- Frequency linearity : $<0.3 \%(\mathrm{DC}-100 \mathrm{kHz})$

- Voltage linearity for SI : $<0.3 \%$

\subsection{Digitizer}

The digitizer is from DR Strauss Company, is mainly used for the lightning and switching impulse measurements and has been fully calibrated and validated at LNE according to IEC 61083-1 [3]. It has been fully characterized, it has the following characteristics:

- Bandwidth : $50 \mathrm{MHz}$

- Sampling frequency: $200 \mathrm{MS} / \mathrm{s}$

- Vertical resolution: 14 bits

- Two channels with 24 ranges each one

- Maximum input voltage : $2000 \mathrm{~V}$

- Rise time : $7 \mathrm{~ns}$

- Internal noise : $<0,1 \%$

- Integral Non Linearity $: \pm 0,1 \%$

- Differential non Linearity $<0,2$ LSB.

- Input impedance: $1 \mathrm{M} \Omega / / 30 \mathrm{pF}$.

\subsection{Soft-ware}

The software for signal processing, WinTR-AS, from DR Strauss Company, is used to collect the data and has been also validated at LNE according to IEC 61083-2 [4] for all the typical waveforms (lightening impulses, chopped impulses, oscillating impulses, switching impulses, rectangular impulses, etc.).

\section{CHARACTERIZATION OF THE DIGITIZER}

\subsection{Calibrator KAL1000}

KAL1000 is a calibrator from DR Strauss Company which used for the calibration of the digitizer before and after each 
calibration. KAL1000 is calibrated by comparison to a continuous voltage, using a standard peak detector as described in figure 3 . The uncertainty of measurement is $0,2 \%$ for the peak value. The Peak detector, itself, is calibrated at DC voltage for static range and with an ideal step voltage for dynamic range.

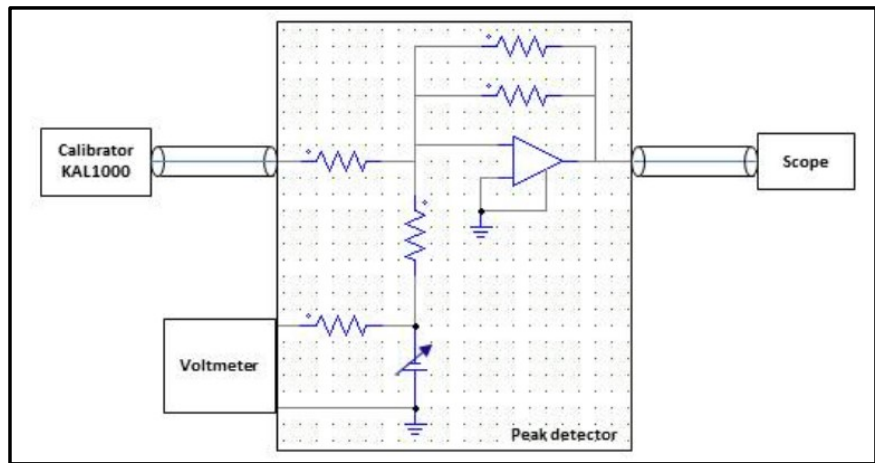

Fig. 3. Calibration of the calibrator KAL1000 using a standard peak detector for voltage up to $500 \mathrm{~V}$.

In-situ measurements involve the temperature corrections, since the operating temperature is often different from that used for the calibration which is in our case $23^{\circ} \mathrm{C} \pm 1^{\circ} \mathrm{C}$. The calibrator is characterized in temperature over a range of $5^{\circ} \mathrm{C}-40^{\circ} \mathrm{C}$. Temperature dependence of the calibrator does not exceed $0,2 \%$ for the voltage, $0,4 \%$ for the front time (LI), $0,6 \%$ for time to peak (SI) and $0,2 \%$ for the time to half value (Both LI and SI). Linearity dependence has been found allowing the possibility to apply corrections if needed.

\subsection{Comparison with the KAL1000.}

In first measurement sessions, the calibrator KAL1000 is used to calibrate the digitizers for lightning and switching impulses for voltages up to $500 \mathrm{~V}$ in positive and negative polarities. The results have shown a maximum deviations of $0,4 \%$ for LI and $0,3 \%$ for SI.

\subsection{Comparison with the Nicolet Power pro}

The new digitizer TR-AS, is compared to the "old" LNE reference digitizer PowerPro from Nicolet Company. LI and SI impulses up to $500 \mathrm{~V}$ are delivered by an impulse voltage generator and simultaneously acquired by the two digitizers. For the "old" system, impulse parameters are calculated using reference software intended to control the digitizer PowerPro. For this characterization, deviations obtained for the peak value are less than $2 \%$. They are due to the use of the attenuators associated with the inputs of the digitizer PowerPro which have maximum admitted voltage of $40 \mathrm{~V}$ peak. Deviations for the front time and the time to half value are in the same order.

\subsection{Comparison with a step voltage}

A standard step calibrator has been used to generate calibrated voltage steps up to $1000 \mathrm{~V}$ based on the mercury relay technology which allows steps with few nanoseconds rise time. The amplitude of the acquired step with the digitizer is calculated and compared to the amplitude of the step. The calculation of the voltage step is performed with several duration starting at $0.25 \mu \mathrm{s}$. The obtained results of channel 1, figure 4 , show a deviation less than $0,1 \%$ for large duration and $0,5 \%$ for short duration. Similar results have been obtained for channel 2. Noted that for LI and SI impulses, the measurements are performed with large durations.

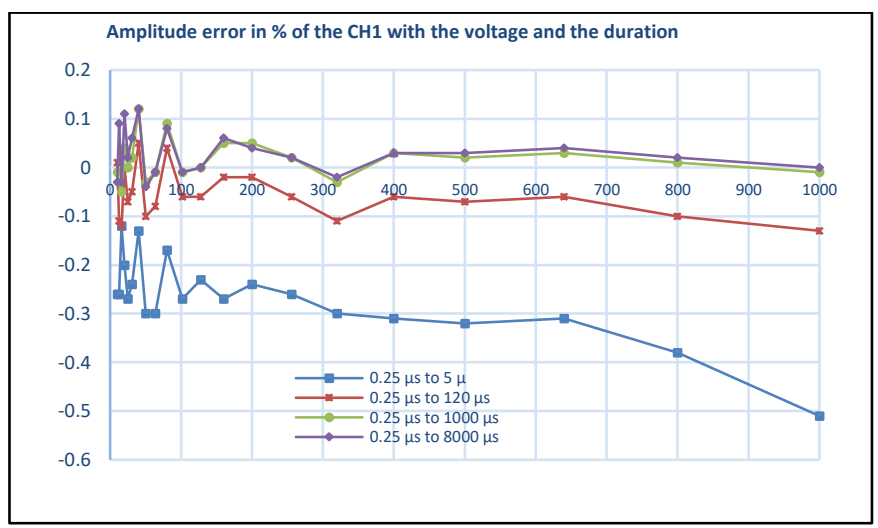

Fig. 4 Characterization of the digitizer with voltage steps

\subsection{Convolution technique}

Convolution technique (IEC 60060-1 Annexe D) has been used to determine the errors of the digitizer for all the ranges and for the two channels. Three type of LI have been tested; $0,84 / 50 \mu \mathrm{s}, 1,25 / 50 \mu \mathrm{s}$ and $1,56 / 50 \mu \mathrm{s}$. One type of SI $250 / 2500 \mu \mathrm{s}$ has been tested. The CH1 results for LI and SI measurements are summarized respectively in figures 5 and 6. The results are in good agreements with the results in figure 4 for voltage up to $500 \mathrm{~V}$. Above $500 \mathrm{~V}$, the errors are less than $0,6 \%$ for LI and less than $0,25 \%$ for SI. Error of time parameters are less than $1 \%$ for both LI and SI.

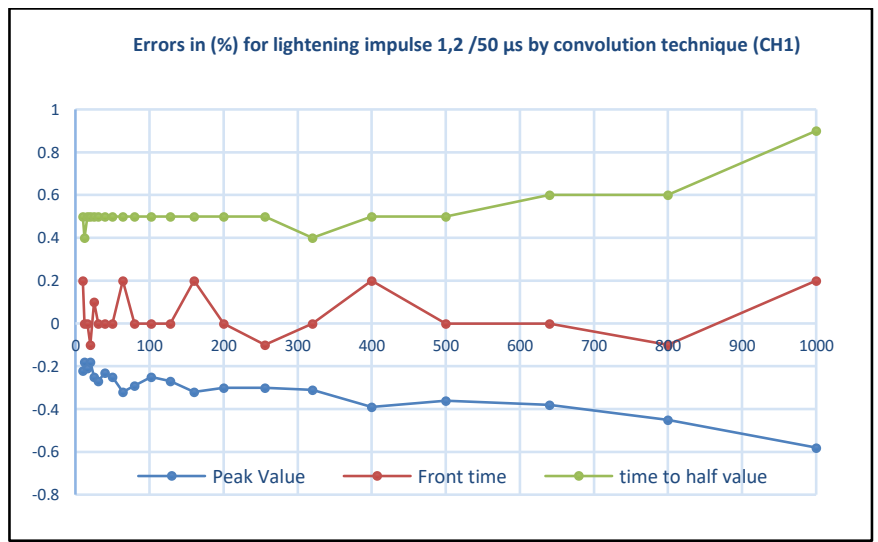

Fig. 5 LI errors using deconvolution technique for 1.2/50 $\mu$ s. 


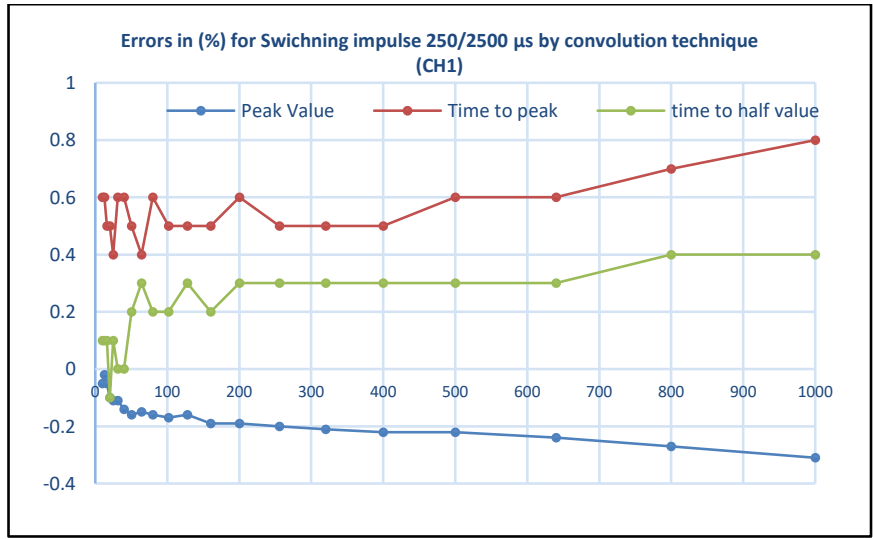

Fig. 6 SI errors using deconvolution technique for $250 / 2500 \mu \mathrm{s}$.

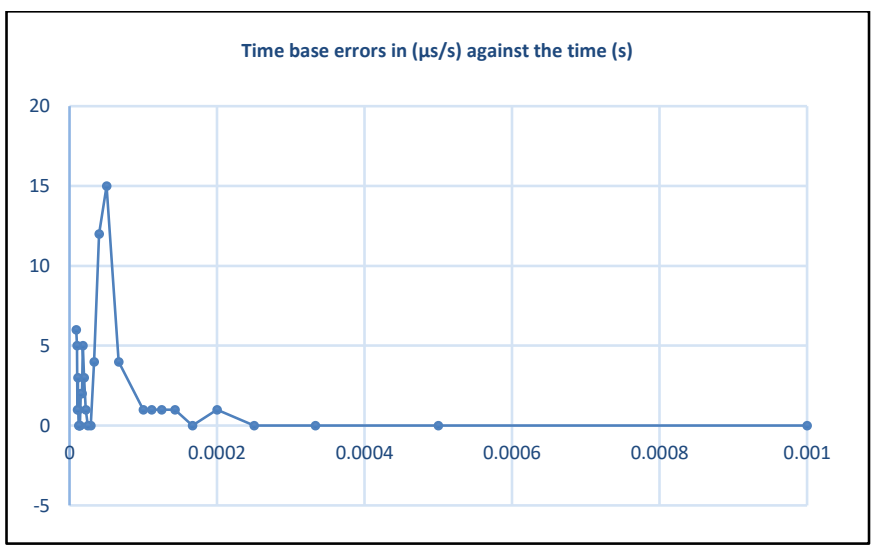

Fig. 7 Time base errors less than 15 ppm.

\subsection{Time base errors}

The characterization of the time base of the digitizer is carried out by comparison with a sinusoidal standard oscillator at maximum digitizer sampling frequency $(200 \mathrm{MHz})$. The maximum error is $15 \mathrm{ppm}$ (figure 7), it is mainly due to the resolution of the digitizer (5 ns). This high accuracy allows better uncertainty for the determination of time parameters.

\subsection{Validation for the Measurement of step responses}

The step response describes the transfer behaviour between the input and output signals for a system. This relationship is expressed by the unit step response in the time domain. The experimental step responses gives valuable information on the transfer behaviour of a measuring system and its components. The characterization was carried out by study the step response of HV measuring systems and their components. The step response is recorded with digitizers and evaluated with software. The old standard digitizer PowerPro is controlled by the MTI software. The obtained parameters of the step response from the digitizers are shown in table 1. For this characterization, a higher exceedance with the standard scope is obtained, since the digitizer has a large bandwidth.
Table 1: obtained parameters of the step response from the digitizers

\begin{tabular}{|c|c|c|c|}
\hline \multirow{2}{*}{$\begin{array}{c}\text { Voltage step } \\
\text { of } 100 \mathrm{~V}\end{array}$} & \multicolumn{2}{|c|}{ Results with MTI } & \multirow{2}{*}{$\begin{array}{c}\text { Results with } \\
\text { WinTR-AS }\end{array}$} \\
\cline { 2 - 3 } & $\begin{array}{c}\text { filtered } \\
\text { signal }\end{array}$ & $\begin{array}{c}\text { unfiltered } \\
\text { signal }\end{array}$ & \\
\hline Overshoot $\beta(\%)$ & 22.3 & 22.3 & 21.6 \\
\hline Settling time ts (ns) & 338.5 & 338 & 178 \\
\hline $\begin{array}{c}\text { Partial response time } \\
\text { Ta (ns) }\end{array}$ & 8.5 & 9.5 & 10.1 \\
\hline $\begin{array}{c}\text { Experimental response } \\
\text { time TN (ns) }\end{array}$ & 9.6 & 9.5 & 2.9 \\
\hline
\end{tabular}

Similar measurements have been found for both digitizers expect for the settling time. In fact, WinTR-AS use of the new algorithm described in IEC 60060-2 annexe C, which, allows very high accuracy for the determination of the Settling time (Uncertainty of about $50 \mathrm{~ns}$ ).

\section{CALIBRATION PROCEDURE}

LNE has developed a test procedure for the calibration of equipment in $\mathrm{HV}$ impulses with metrological traceability connected to the international system of unit (SI).

For calibration in LNE HV laboratory, LNE has purchased a $\mathrm{HV}$ generator $400 \mathrm{kV} / 20 \mathrm{~kJ}$ to perform the calibration of lightning impulses for voltages up to $360 \mathrm{kV}$ and switching impulses for voltages up to $240 \mathrm{kV}$. For in situ calibrations, the levels are $420 \mathrm{kV}$ for LI and 500 for SI depending the facilities of the costumers.

The calibration is performed in 5 successive steps:

1) The digitizer TR-AS is calibrated by comparison to the impulse calibrator at the same conditions of use (temperature, channels and ranges). Complementary measurements could be done with step voltages Measurements.

2) Determination of the scale factor of the dividers (reference divider and divider under calibration), it is performed at $60 \mathrm{~Hz}, 1 \mathrm{kHz}$ and $10 \mathrm{kHz}$. The output voltage and the input voltage are measured by two calibration standards voltmeters.

3) Determination of step response of the dividers, associated with their damping resistors, is performed with a high quality step generator placed, if possible, at the same height of the dividers. This step is important to check the dynamic of the dividers.

4) The interference test of the dividers is checked. A chopped wave, or full wave, is applied simultaneously on both measuring systems at maximum voltage. One is used for the impulse measurement and the transmission cable of the other is disconnected and matched with its impedance for interference check. Interference of a given measuring system is defined as the ratio between the peak-topeak value amplitude of the measured interference signal and the peak amplitude of the impulse that 
would have been measured if its measuring cable had been connected.

5) HV voltage measurements by comparing the results of the reference system and the system under calibration up to the maximum voltage, $420 \mathrm{kV}$ for LI and $500 \mathrm{kV}$ for SI. The reference HV arrangement in LNE is presented in figure 8 , for in-situ calibration distances could be arranged to take into account the characteristics of the HV testing laboratory.

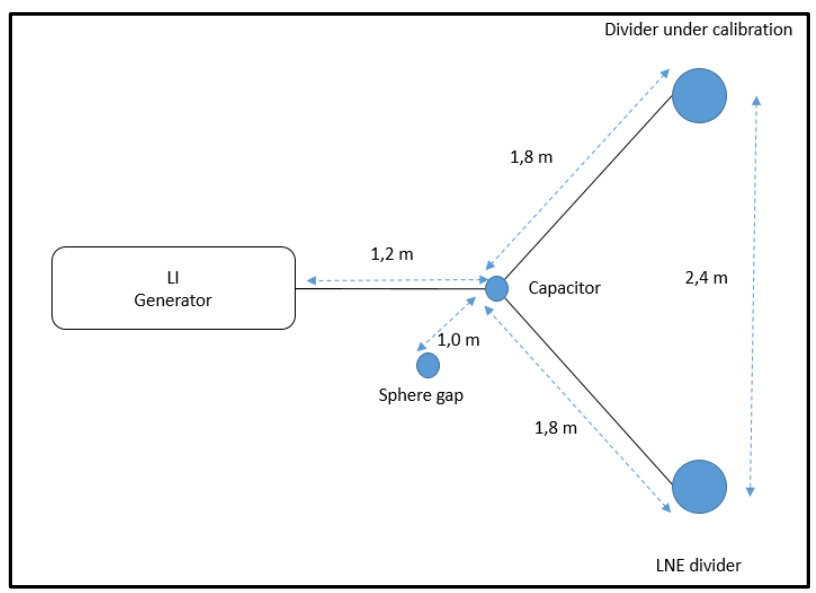

Fig 8. Configuration used during the H.V measurement in LNE laboratory (height of injection point is minimum at 2,0 m)

Finally, Steps 1 and 2 are repeated at the end of the HV measurements (deviation could be observed and usually due to temperature or self-heating of the dividers).

\section{UNCERTAINTY OF MEASUREMENTS}

The uncertainty of the measurement associated to the results and a complete uncertainty budget is evaluated according to the guide to the expression of uncertainty in measurement (JCGM 100:2008).

The expanded uncertainties are summarized in the table 2 and 3 .

Table 2 : Uncertainty of measurement for LI up to $420 \mathrm{kV}$

\begin{tabular}{|c|c|c|c|c|}
\hline \multirow{2}{*}{ Wave shape } & \multicolumn{4}{|c|}{ Uncertainty of measurement in \% (k=2) } \\
\cline { 2 - 5 } & Peak Value & Front time & $\begin{array}{c}\text { Time to } \\
\text { chopping }\end{array}$ & $\begin{array}{c}\text { Time to Half } \\
\text { Value }\end{array}$ \\
\hline $0,84 / 50 \mu \mathrm{s}$ & 0,5 & 2,0 & - & 0,8 \\
\hline $1,56 / 50 \mu \mathrm{s}$ & 0,5 & 2,0 & - & 0,8 \\
\hline $\begin{array}{c}\text { Chopped at } \\
0.5 \mu \mathrm{s}\end{array}$ & 1,5 & 3,0 & 1,5 & - \\
\hline
\end{tabular}

Table 3 : Uncertainty of measurement for SI up to $500 \mathrm{kV}$

\begin{tabular}{|c|c|c|c|}
\hline \multirow{2}{*}{ Wave shape } & \multicolumn{3}{|c|}{ Uncertainty of measurement in \% (k=2) } \\
\cline { 2 - 4 } & Peak Value & Time to Peak & $\begin{array}{c}\text { Time to Half } \\
\text { Value }\end{array}$ \\
\hline $20 / 1000 \mu \mathrm{s}$ & 0,5 & 2.5 & 1,0 \\
\hline $250 / 2500 \mu \mathrm{s}$ & 0,5 & 5 & 1,0 \\
\hline $300 / 4000 \mu \mathrm{s}$ & 0,5 & 5 & 1,0 \\
\hline
\end{tabular}

\section{CONCLUSION}

Two high accuracy reference systems for the calibration of HV impulses have been developed at LNE to satisfy the new requirements of IEC60060-1 and IEC 60060-2. The first system is intended for the calibration of full lightening impulses up to $420 \mathrm{kV}$ or chopped lightning impulses down to $0,5 \mu \mathrm{s}$. The second one is for Switching impulse measurements up to $500 \mathrm{kV}$, the time to peak could vary from $20 \mu \mathrm{s}$ to $300 \mu \mathrm{s}$ and the time to half value could vary from $1000 \mu \mathrm{s}$ to $4000 \mu \mathrm{s}$. A test procedure to reach high accuracy has been developed and could be easy implemented for in-situ calibrations. Linearity extension offers the possibility to ensure the traceability for voltage up to $2.1 \mathrm{MV}$ for lightening impulse and 2.5 MV for switching impulses.

\section{REFERENCES}

[1] IEC 60060-1:2010, "High-voltage test techniques - Part 1: General definitions and test requirements".

[2] IEC 60060-1:2010, "High-voltage test techniques - Part 2: Measuring systems".

[3] IEC 61083-1:2001, "Instruments and software used for measurement in high-voltage impulse tests - Part 1: Requirements for instruments".

[4] IEC 61083-2:2011, "Instruments and software used for measurement in high-voltage impulse tests - Part 1: requirements for software for tests with impulse voltages and currents".

[5] Rapport LCIE n ${ }^{\circ} 1188$ et 1246 "Etude et caractérisation d'un système de mesure pour hautes tensions impulsionnelles de foudre", 1993.K. Elissa, "Title of paper if known," unpublished.

[6] Rapport d'étude BNM $\mathrm{n}^{\circ}$ 1418A "Etalon pour hautes tensions impulsionnelles", 1999 Gérard Genevès.

[7] EURAMET.EM-S42: "Comparison of lightning impulse (LI) Reference Measuring Systems" 